\title{
Anti-leishmanial Activity of Methanolic Extract of Nerium oleander L. against Leishmania major
}

Hamed Noormohammadi (MSc)

Department of Parasitology, School of Medicine, Zabol University of Medical Sciences, Zabol, Iran

Yahya Maroufi (PhD)

Department of Parasitology, School of Medicine, Kurdistan University of Medical Sciences, Sanandaj, Iran

Mansour Dabirzadeh (PhD)

Department of Parasitology, School of Medicine, Zabol University of Medical Sciences, Zabol, Iran

Abdolhossein Miri (PhD)

Department of Pharmacognosy, Faculty of Pharmacy, Zabol University of Medical Sciences, Zabol, Iran

Corresponding author: Yahya Maroufi

Email: maroofi.y@gmail.com Tel: +989183755825

Address: Department of Parasitology, School of Medicine, Kurdistan University of Medical Sciences, Sanandaj, Iran

Received : 23 Apr 2016

Revised: 02 Jul 2016

Accepted: $10 \mathrm{Jul} 2016$

\begin{abstract}
IBSTRACT
Background and Objectives: Leishmaniasis is a public health problem caused by the protozoan Leishmania. Pentavalent antimonials are currently used for treatment of leishmaniasis, but they have serious side effects. Nerium oleander L. has been used in traditional medicine due to its various health-protective properties. This study aimed to investigate anti-leishmanial activity of $N$. oleander L. leaves extract against Leishmania major promastigotes and amastigotes in vitro.

Methods: L. major promastigotes were cultured in RPVI 1640 medium supplied with $10 \%$ fetal bovine serum. Different concentrations were prepared from the extract and added to $\mathrm{L}$. major promastigotes seeded in 96-well plates. Viability percentage was evaluated by direct counting and MTT assay after 24, 40 and 72 hours. To investigate the cytotoxic effect of $N$. oleander L. on L. major amastigotes, the plant extract was added to amastigotes cultured in intraperitoneal macrophages. The mean number of amastigotes was calculated by direct counting after 24 and 48 hours.

Results: All concentrations of the extract significantly reduced the viability of promastigotes when compared with the controls. Half-maximal inhibitory concentration was estimated to be $22.21 \mu \mathrm{g} / \mathrm{ml}$ after 24 hours. Percentage of cytotoxicity in amastigotes exposed to $20 \mu \mathrm{g} / \mathrm{ml}$ of the extract was $53.61 \%$ and $53.27 \%$ after 24 and 40 hours, respectively. In addition, percentage of cytotoxicity in amastigotes exposed to $80 \mu \mathrm{g} / \mathrm{ml}$ of the N. oleander L. extract was $53.77 \%$ and $55.40 \%$ after 24 and 40 hours, respectively.

Conclusion: The N. oleander L. extract exerts anti-leishmanial activity on L. major promastigotes in a time- and dose-dependent manner.

Keywords: Leishmania major, Nerium.
\end{abstract}




\section{INTRODUCTION}

Leishmaniasis is caused by various flagellate protozoa belonging to the Leishmania genus. Clinical manifestations of leishmaniasis include three major forms: cutaneous, mucocutaneous and visceral. According to epidemiological studies, there are almost 12 million cases of leishmaniasis worldwide, with 2 million new cases occurring annually and 350 million people at risk of infection. Leishmaniasis is considered as an important public health problem, causing morbidity, mortality and financial loss (1). Pentavalent antimonials (meglumine and sodium stibogluconate) have been used as the first line therapy since 60 years ago (2). However, these drugs have been accompanied with some limitations including long treatment period, high-cost, painful injection, and severe toxicity for various organs, treatment failure and risk of relapse $(3,4)$.

Phytomedicine has been commonly used because of certain advantages such as lowcost, availability, low toxicity and no need for injection (5). Nerium oleander L. is a toxic and evergreen shrub belonging to family Apocynaceae. It is one of the most poisonous commonly grown garden plants (6). Nerium contains various compounds including oleandrin, oleanderigenine, nerine, neriantine, folinerin, flavonoids, tannins, resin, kaneric acid and alkaloids (7-9). Various parts of $N$. oleander $\mathrm{L}$. have been used in herbal medicine due to their cardiotonic, antibacterial, anticancer, cytotoxic, antiplatelet aggregation, anti-inflammatory and antiviral properties (8, 10-13). In addition to anti-parasitic activity, the plant leaves have been used for treatment of edema, scabies and itching, desquamation, and lower back and knee pain (14). This study aimed to investigate cytotoxic effects of $N$. oleander L. leaves extract on $L$. major promastigotes and amastigotes in vitro.

\section{MATERIAL AND METHODS}

$N$. oleander L. was collected from Zabol University of Medical Sciences campus, Iran. Identity of the plant was verified at Ferdowsi University with herbarium code 2718. The plant was dried at room temperature, and then extracted using $80 \%$ methanol. The extract was stored at room temperature until methanol evaporated completely. Next, a $2 \mathrm{mg} / \mathrm{ml}$ stock solution was prepared by dissolving the extract powder in normal saline. After passing the solution through $0.2 \mu$ filters, various concentrations $(10,20,30,60,125$ and 250 $\mu \mathrm{g} / \mathrm{ml})$ were prepared from the stock solution.

Standard Iranian strain of $L$. major (MRHO/IR/75/ER) was obtained from the Tarbiat Modares University, Iran. Promastigotes were cultured in RPMI 1640 medium (ATOCEL, Austria) with 10\% heatinactivated fetal bovine serum (FBS) (ATOCEL, Austria), and incubated at $21^{\circ} \mathrm{C}$ for 72 hours. Logarithmic phase promastigotes $\left(10^{6} \mathrm{cell} / \mathrm{ml}\right)$ were added to 96 -well plates (ATOCEL, Austria). Different concentrations of the $N$. oleander L. extract were added to the wells and the plate was incubated at $21{ }^{\circ} \mathrm{C}$ for 72 hours. Wells containing promastigotes without the plant extract were considered as negative control. Four wells were dedicated for each concentration. Cell viability percentage was calculated by direct counting and MTT assay after 24, 48 and 72 hours. MTT assay is colorimetric technique for assessing cell activities such as growth, proliferation, viability and cytotoxicity. The assay is based on the cleavage of the yellow tetrazolium salt, MTT, to form a soluble blue formazan product by mitochondrial enzymes, and the amount of formazan produced is directly proportional to the number of living cells present during MTT exposure (15). MTT powder was purchased from Sigma (Germany) and dissolved in phosphate buffered saline. The $5 \mathrm{mg} / \mathrm{ml}$ solution was passed through 0.2 $\mu \mathrm{m}$ filters. MTT was added to all wells, and the plate was incubated at $21^{\circ} \mathrm{C}$ in dark for 35 hours. Then, $100 \mu \mathrm{L}$ of dimethyl sulfoxide was added to the wells. After $10 \mathrm{~min}$, optical density (OD) of the plate was read by an ELISA reader at $620 \mathrm{~nm}$. Percentage of cytotoxicity was determined based on the following formula: Toxicity $=[1-(\mathrm{AT}-\mathrm{AB}) /$ $(\mathrm{AC}-\mathrm{AB})] \times 100(\mathrm{AB}: \mathrm{OD}$ of blank well, $\mathrm{AC}$ : OD of control, AT: OD of treated cells) (16).

Macrophages were extracted from periotic bone of laboratory mouse by injection and aspiration of $3 \mathrm{~mL}$ sterile PBS. Round sterile coverslips were placed at the bottom of the wells of a 12-well plate, and then $10^{5}$ macrophages $/ \mathrm{mL}$ were added to each well containing RPMI 1640 medium with 10\% FBS and $0.5 \%$ gentamicin. The plates were incubated at $37{ }^{\circ} \mathrm{C}$ and $5 \% \mathrm{CO}_{2}$. After 24 hours, $10^{6}$ stationary-phase promastigotes were added to the wells, and the plate was incubated 
at $37{ }^{\circ} \mathrm{C}$ and $5 \% \mathrm{CO}_{2}$ again. After 24 hours, supernatant was discarded and replaced with fresh medium with $10 \%$ FBS (17). Then, 20 $\mu \mathrm{g} / \mathrm{ml}$ and $80 \mu \mathrm{g} / \mathrm{ml}$ of $N$. oleander L. extract were added to the wells containing macrophages infected with amastigotes. Wells containing macrophages without the plant extract were considered as negative control. Mean number of amastigotes in 100 infected macrophages was calculated by direct counting after 24 and 48 hours (18). Data were analyzed in SPSS (version 16) using one-way ANOVA. The percentage of amastigotes killed was calculated by comparing the mean number of amastigotes with the control group. Pvalues less than 0.05 were considered as statistically significant.

\section{RESULTS}

Figure 1 shows the effect of different concentrations $N$. oleander L. extract on viability of promastigotes after 24,48 and 72 . All concentrations of the extract reduced the viability of promastigotes significantly compared to the controls $(\mathrm{P}<0.05)$. Moreover, the half-maximal inhibitory concentration $\left(\mathrm{IC}_{50}\right)$ was $22.21 \mu \mathrm{g} / \mathrm{ml}$ after 24 hours.

Treatment with $20\left(\mathrm{IC}_{50}\right)$ and $80 \mu \mathrm{g} / \mathrm{ml}$ of the $N$. oleander L. extract significantly reduced the number of amastigotes in macrophages compared with the controls (Table 1). Figure 2 represents the anti-leishmanial activity of the extract against intra-macrophagic amastigotes in form of cytotoxicity percentage.

Figure 1- Effect of different concentrations of $N$. oleander L. extract on viability of promastigotes after 24, 48 and 72 hours

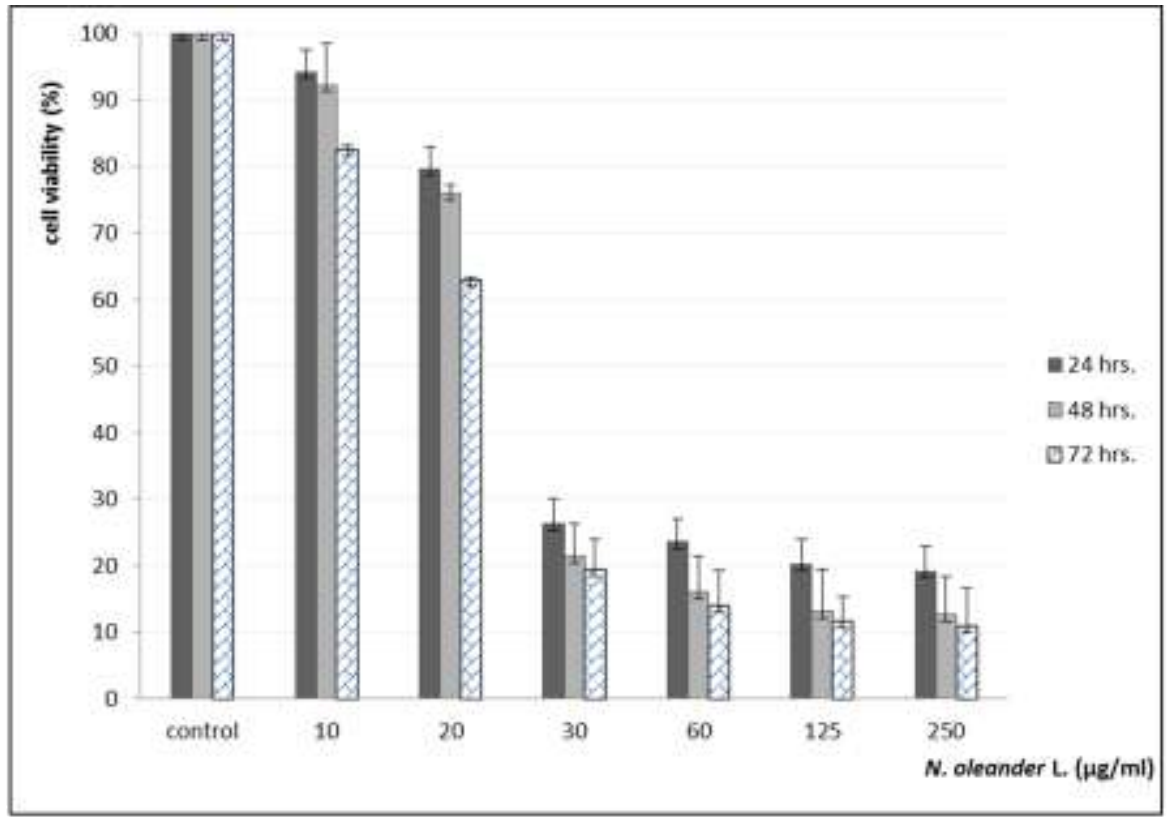

Table 1- The mean number of intra-macrophagic amastigotes in the treatment and control groups

\begin{tabular}{crrr}
\hline $\begin{array}{c}\text { Control } \\
\text { Time }\end{array}$ & & Treatment with $20 \mu \mathrm{g} / \mathrm{ml}$ of the extract & Treatment with $80 \mu \mathrm{g} / \mathrm{ml}$ of the extract \\
\hline 24 hours & $12.64 \pm 1.15$ & $6.8 \pm 0.55$ & $6.78 \pm 0.51$ \\
48 hours & $15.86 \pm 0.57$ & $8.8 \pm 0.57$ & $8.45 \pm 0.50$ \\
\hline
\end{tabular}


Figure 2- Anti-leishmanial activity (cytotoxicity percentage) of $N$. oleander L. extract against intra-macrophagic amastigotes after 24 and 48 hours

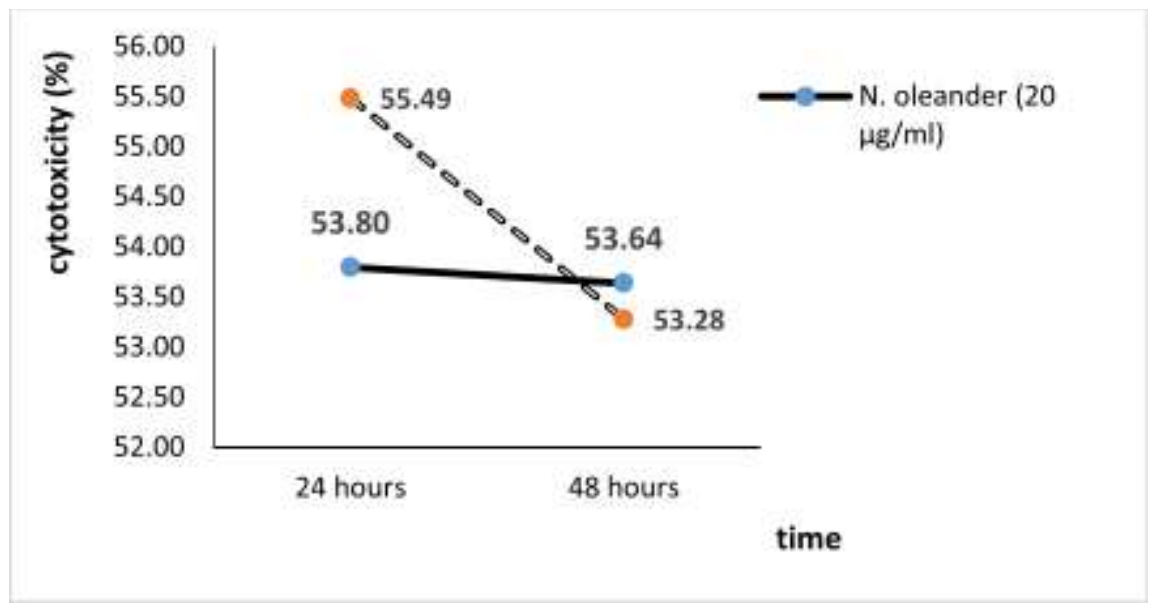

\section{DISCUSSION}

The results of this study showed that extract of $N$. oleander $\mathrm{L}$. has cytotoxic effects on the promastigote and amastigote of $L$. major in a time- and dose-dependent manner. The highest cytotoxicity was caused by 250 $\mu \mathrm{g} / \mathrm{ml}$ of the $N$. oleander $\mathrm{L}$. extract after 72 hours. In the present study, we investigated the cytotoxic effect of the $\mathrm{IC}_{50}(20 \mu \mathrm{g} / \mathrm{ml})$ of the extract and a higher dose $(80 \mu \mathrm{g} / \mathrm{ml})$ on $L$. major amastigotes. Similar to promastigotes, the cytotoxic effects on amastigotes were timeand dose-dependent in a way that treatment with $80 \mu \mathrm{g} / \mathrm{ml}$ of the $N$. oleander $\mathrm{L}$. extract caused $55.48 \%$ toxicity. A study investigated the effect of a mixture of $N$. oleander L. leaf with Ricinus communis oil, Capsicum spp. seeds and almond on L. major promastigotes. Treated and non-treated promastigotes were injected to laboratory mice and lesions' size and formation time were investigated after seven weeks. The mentioned study reported that the mixture had significant inhibitory effects on the progression of cutaneous lesions in the test group when compared with the control group (19). However, we investigated the cytotoxic effect of the $N$. oleander $\mathrm{L}$. extract alone on Leishmania promastigotes and amastigotes. Although several studies have investigated the cytotoxic effects of Nerium on different organisms, there is no data about the effect of Nerium extract against other parasites $(20,21)$. A study reported that $50 \%$ cytotoxicity concentration of $N$. oleander $\mathrm{L}$. on herpes simplex virus- 1 is $4.73 \mu \mathrm{g} / \mathrm{ml}(22,23)$. Another study showed that the $N$. oleander L. extract has potent antimicrobial activity against Pseudomonas aeruginosa and Bacillus subtilis but not on Candida albicans. Some studies suggested that the antimicrobial activity of the plant could be attributed to the presence of flavonoids (24-27).

\section{CONCLUSION}

The $N$. oleander L. extract exerts antileishmanial activity on L. major promastigotes in a time- and dose-dependent manner.

\section{ACKNOWLEDGMENTS}

The authors would like to thank the Parasitology Laboratory of Zabol University of Medical Sciences for their support.

\section{CONFLICT OF INTEREST}

The authors declare that there is no conflict of interest. 


\section{REFERENCES}

1. Alvar J, Velez ID, Bern C, Herrero M, Desjeux P, Cano J, et al. Leishmaniasis Worldwide and Global Estimates of Its Incidence. Plos One. 2012; 7(5): e35671. doi: 10.1371/journal.pone.0035671.

2. Croft SL, Yardley V. Chemotherapy of leishmaniasis. Curr Pharm Design. 2002; 8(4): 319-42.

3. Croft SL, Coombs GH. Leishmaniasis - current chemotherapy and recent advances in the search for novel drugs. Trends Parasitol. 2003; 19(11): 502-8.

4. Arevalo I, Ward B, Miller R, Meng T, Najar E, Alvarez E, et al. Successful Treatment of Drug-Resistant Cutaneous Leishmaniasis in Humans by Use of Imiquimod, an Immunomodulator. Clin Infect Dis. 2001;33(11):1847-51.

5. Sen R, Chatterjee M. Plant derived therapeutics for the treatment of Leishmaniasis. Phytomedicine. 2011;18(12):1056-69.

10.1016/j.phymed.2011.03.004

6. Akosy A, Ozturk M.A. Nerium oleander L. as a biomonitor of lead and other heavy metal pollution in Mediterranean environments. Sci Total Environ. 1997; 205(2-3): 145-150.

7. Siddiqui BS, Khatoon N, Begum S, Farooq AD, Qamar K, Bhatti HA, et al. Flavonoid and cardenolide glycosides and a pentacyclic triterpene from the leaves of Nerium oleander and evaluation of cytotoxicity. Phytochemistry. 2012; 77: 238-44. doi: 10.1016/j.phytochem.2012.01.001.

8. Langford SD, Boor PJ. Oleander toxicity: An examination of human and animal toxic exposures. Toxicol. 1996; 109(1):1-13

9. Siddiqui S, Hafeez F, Begum S, Siddiqui BS. Kaneric Acid, a New Triterpene from the Leaves of NeriumOleander. J Nat Prod. 1986; 49(6):1086-90. DOI: 10.1021/np50048a019.

10. Zia A, Siddiqui BS, Begum S, Siddiqui S, Suria A. Studies on the constituents of the leaves of Nerium oleander on behavior pattern in mice. J Ethnopharmacol. 1995; 49(1): 33-9.

11. Siddiqui BS, Begum S, Siddiqui S, Lichter W. 2 Cytotoxic Pentacyclic Triterpenoids from NeriumOleander. Phytochemistry. 1995; 39(1): 171-4.

12. Pathak S, Multani AS, Narayan S, Kumar V, Newman RA. Anvinel (TM), an extract of Nerium oleander, induces cell death in human but not murine cancer cells. Anti-Cancer Drug 2000;11(6):455-63.

13. Begum S, Siddiqui BS, Sultana R, Zia A, Suria A. Bio-active cardenolides from the leaves of Nerium oleander. Phytochemistry 1999; 50(3): 435-8.

14. Nitave SA, Patil VA. Comparative evaluation of anthelmintic activity of Nerium indicum, mill flower extract and punica Granatum, linn peel and seed extract in 1:1 ratio and their phytochemical screening. World $\mathrm{J}$ Pharm Pharm Sci. 2014; 3(6): 1438-47.
15. Sylvester PW. Optimization of the tetrazolium dye (MTT) colorimetric assay for cellular growth and viability. Methods Mol Biol. 2011;716:157-68. doi: 10.1007/978-1-61779-012-6_9.

16. Maroufi Y, Ghaffarifar F, Dalimi A, Sharifi Z, Hassan Z. Effect of Cantharidin on Apoptosis of the Leishmania major and on Parasite Load in BALB/C Mice. Research Journal of Parasitology. 2013; 8(1):1425. DOI: 10.3923/jp.2013.14.25.

17. Dalimi A, Delavari M, Ghaffarifar F, Sadraei J. In vitro and in vivo antileishmanial effects of aloe-emodin on Leishmania major. J Tradit Complement Med. 2015; 5(2): 96-9. doi: 10.1016/j.jtcme.2014.11.004.

18. Ghaffarifar F. Leishmania major: in vitro and in vivo anti-leishmanial effect of cantharidin. Exp Parasitol. 2010; 126(2): 126-9. doi: 10.1016/j.exppara.2010.04.004.

19. Yakhchali M, Ranjbari-Kijandabeh M. Effects of Nerium oleander leaf, Ricinus communis oil, Capsicum spp. seeds, and almond compound on cutaneous leishmaniasis caused by Leishmania species under laboratory condition and its effect on cutaneous lesion progression in mice. Sci J Kurdistan Univ Med Sci. 2013; 18:13-19.[Persian]

20. Singh S, Singh DK. Molluscicidal activity of Nerium indicum bark. Braz J Med Biol Res 1998; 31(7): 951-4.

21. El-Shazly MM, El-Zayat EM, HermersdÖRfer H. Insecticidal activity, mammalian cytotoxicity and mutagenicity of an ethanolic extract from Nerium oleander (Apocynaceae). Annals of Applied Biology. 2000; 136(2): 153-7.

22. Farahani M. Antiviral Effect Assay of Thymus Kotschyanus and Nerium Oleander on HSV-1 in Vitro. Journal of Shahid Sadoughi University of Medical Sciences. 2013; 21(2): 189-96 [Persian].

23. Farahani M. Anti-Herpes Simplex Virus Effect of Camellia sinesis, Echiumamoenum and Nerium oleander. Journal of Applied \& Environmental Microbiology. 2014; 2(4): 102-5. DOI: 10.12691/jaem-2-4-3.

24. Uzair A, Bakht J, Iqbal A, Naveed K, Ali N. In vitro antimicrobial activities of different solvent extracted samples from Iris germinica. Pak $\mathrm{J}$ Pharm Sci. 2016;29(1);145-150.

25. Kumar S, Selva RKRM, Pavunraj M, Bhattacharya D. Aantibacterial therapeutic role of thespesia populnea, nerium odorum and ocimum basilicum on selected human pathogenic microorganisms. Journal of Pharmacy Research. 2012; 5(8): 4271-74.

26. Hussain MA. Gorsi MS. Antimicrobial activity of Nerium oleander Linn. Asian J Plant Sci. 2004; 3(2): $177-80$.

27. Derwich E. Benzian Z, Boukir A. Antibacterial activity and chemical composition of the essential oil from flowers of Nerium oleander. Electronic Journal of Environmental, Agricultural and Food Chemistry. 2010; 9(6): 1074-84. 